\title{
Degranulação de neutrófilos ex-vivo por ação do polímero de amido de mandioca
}

\author{
Degranulation of neutrophils ex-vivo by the action of polymer cassava's starch
}

\author{
Marcos Antonio da Silva Cristovam ${ }^{\mathrm{I}}$ Gentil Ferreira Gonçalves ${ }^{\mathrm{II}}$ Orlando Seiko Takemura ${ }^{\mathrm{II}}$ \\ Ana Paula Inoe Tomasini" ${ }^{\text {II }}$ Douglas Dragunski ${ }^{\text {II }}$ Joice Reolon ${ }^{\text {II }}$ Juliana Oliveira Gomes ${ }^{\text {II }}$ \\ William Megda ${ }^{\text {II }}$
}

\section{RESUMO}

Os neutrófilos têm papel essencial na defesa do hospedeiro contra infecções. Quando estimulados respondem com aumento do consumo de oxigênio denominado "explosão respiratória”, que gera grande quantidade de ânion superóxido e peróxido de hidrogênio, os quais desempenham importante função antimicrobiana, e subsequente degranulação de neutrófilos. Os polímeros são materiais amplamente utilizados em medicina veterinária. Vários estudos vêm sendo realizados na busca de novos polímeros e sua biocompatibilidade para uso médico. Um polímero de amido de mandioca (Manihot esculenta crantz) foi produzido no Laboratório de Química da Universidade Paranaense - Campus Umuarama, com objetivo de analisar a possibilidade de ocorrer degranulação de neutrófilos quando expostos ao amido. Os resultados iniciais mostraram uma ação bioinerte do polímero de amido de mandioca em diferentes concentrações quando colocado junto com neutrófilos. Dessa forma, este material tem aplicação potencial em biomateriais.

Palavras-chave: neutrófilos, produção de ânion superóxido, polímeros biodegradáveis, biomateriais, amido de mandioca.

\section{ABSTRACT}

The neutrophils play an essential role in host defenses against infection. When stimulated it responds with an increase of consumption of oxygen known as 'respiratory burst', so generating a great quantity of superoxide anion and hydrogen peroxide, which play an important function antimicrobial, and subsequent degranulation of neutrophils. Polymers are materials largely used in veterinary medicine. Several studies have been carried out to find new polymers and their biocompatibility to medical use. One polymer of cassava's starch (Manihot esculenta crantz) was developed at the
Paranaense University's Laboratory of Chemistry - Campus Umuarama City, aiming to analyze the neutrophils degranulation after exposition to this starch. The early results showed a bioinert action of the polymer of cassava's starch on different concentrations when it was in contact with neutrophils. Thus, this material is potentially indicated as biomaterial.

Key words: neutrophils, superoxide anion production, biodegradable polymers, biomaterials, cassava's starch.

\section{INTRODUÇÃO}

Os neutrófilos quando estimulados secretam grânulos contendo enzimas degradativas e agentes antimicrobianos (BARBIOR, 1978; TAKEMURA et al., 1997). Entre as funções neutrofílicas, o engolfamento do patógeno seguida da liberação de substâncias tóxicas, tais como as Espécies Reativas de Oxigênio (EROs) e enzimas proteolíticas constituem a fase final da defesa. As EROs mais conhecidas são o ânion superóxido, peróxido de hidrogênio, radicais hidroxila e hipoclorito. A NADPHoxidase (Nicotinamida-adenina-dinucleotídeofosfato) é um complexo enzimático multicomponente localizado na membrana plasmática, responsável pela produção de ânion superóxido em uma "explosão respiratória” caracterizada por rápido aumento no consumo de oxigênio. O ânion superóxido produzido é a fonte de todas as EROs geradas no neutrófilo. A NADPHoxidase dos neutrófilos pode ser ativada por

ICurso de Medicina, Universidade Estadual do Oeste do Paraná (UNIOESTE), 85819-110, Cascavel, PR, Brasil. E-mail: ma.cristovam@uol.com.br. Autor para correspondência.

IIUniversidade Paranaense (UNIPAR), Umuarama, PR, Brasil. 
vários fatores como: bactérias, partículas de látex, cálcio e ativadores da proteinocinase como o peptídeo fMLP (formyl-methionil-leucyl-phenylalanine) e PMA (Phorbol-12-myristate-13-acetate). Quando uma célula é ativada pelo fMLP por exemplo, ocorre uma explosão oxidativa. Em neutrófilos humanos, várias proteinocinases estão implicadas na regulação da atividade da NADPHoxidase, a família proteinocinase $\mathrm{C}$ parece ter um papel maior após ativação pelo fMLP (EL-BENNA et al., 2005). A citocalasina B(CB) também é necessária para a liberação de enzimas lisossomiais induzidas pelo fMLP, os quais aumentam a fosforilação da tirosina.

Os polímeros biodegradáveis para uso em medicina veterinária têm sido estudados extensivamente. Atualmente o interesse por polímeros biodegradáveis tem ganhado importância, já que quando usados em sistemas de implantes eles têm a vantagem de não requerer a remoção no final do tratamento devido a sua degradação fisiológica e excreção pelo organismo. Isto é um benefício porque diminui o estresse do animal, não necessita de manejo após implantação e diminui o custo (WINZENBURG et al., 2004). Os polímeros são cadeias longas compostas de unidades unidas covalentemente, os monômeros, agrupados para formar uma estrutura comum.

Constitui o grupo mais extenso dos biomateriais. Estas cadeias longas de moléculas orgânicas são versáteis em composição e propriedades, tornando-as úteis para a confecção de instrumental cirúrgico, dispositivos para implantes, revestimento de dispositivos, cateteres, enxertos vasculares, biomateriais injetáveis e terapêuticos. O amido é um dos biopolímeros mais utilizados para compor materiais biomédicos pelo seu baixo custo, facilidade de fabricação, amplo uso, versatilidade e disponibilidade (WOO et al., 2005).

Na literatura são escassos os trabalhos com biomateriais obtidos de polímeros de amido de mandioca. O objetivo deste trabalho foi avaliar a porcentagem de degranulação de neutrófilos de coelhos frente a um polímero de amido de mandioca e comparando este grupo com neutrófilos estimulados pelo fMLP e citocalasina B desenvolvido no Laboratório de Química da Universidade Paranaense Campus de Umuarama.

\section{MATERIAL E MÉTODOS}

\section{Obtenção dos Neutrófilos}

Foram selecionados oito coelhos da raça Nova Zelândia, com peso médio de 3,5kg (3 a 4,3kg), isentos de quaisquer doenças ou gestação, de ambos os sexos, entre 10 e 16 meses de idade, mantidos em gaiolas individuais no Hospital Veterinário da Universidade Paranaense Campus Umuarama, com água e ração ad libitum, temperatura ambiente, umidade relativa e mantidos sob ciclo dia/noite natural. Os coelhos foram anestesiados com injeção intramuscular de cloridrato de cetamina (Ketamina Agener ${ }^{R}$ a 10\%) $0,1 \mathrm{ml} \mathrm{kg}^{-1}$; cloridrato de xilazina a $2 \%$ (Dorcipec $^{\mathrm{R}}$ ) $0,1 \mathrm{ml}$ $\mathrm{kg}^{-1}$ e cloridrato de fentanila (Fentanest ${ }^{\mathrm{R}} 0,05 \mathrm{mg} \mathrm{ml}^{-1}$ ) $0,1 \mathrm{ml} \mathrm{kg}^{-1}$. A seguir realizou-se tricotomia do abdome do coelho e antissepsia com solução de polivinilpirrolidona-iodo degermante e álcool a $70 \%$ ou polivinil-pirrolidona-iodo tópico. Após a anestesia e antissepsia, realizou-se paracentese abdominal em linha média ventral a $1 \mathrm{~cm}$ caudal à cicatriz umbilical, com cateter (Angiocat ${ }^{\mathrm{R}}$ ) 20G e, após atingir o peritônio, infundiu-se solução glicogenada a $0,2 \%, 200 \mathrm{ml}$, a qual produz reação inflamatória no peritônio por irritação, seguindo-se a retirada do cateter. O coelho era mantido em jejum absoluto por seis horas antes do experimento e após este era devolvido ao plantel do Hospital Veterinário.

Após cinco horas da infusão peritonial os animais foram submetidos aos mesmos procedimentos de anestesia e antissepsia e, a seguir, submetidos a duas paracenteses abdominais simultâneas, uma no quadrante superior esquerdo, na qual foram infundidos $500 \mathrm{ml}$ de solução salina isotônica a $0,85 \%$, e uma na região epigástrica, para a retirada do lavado peritoneal, em torno de 500ml também, o qual foi colhido em bolsa de coleta de silicone com anticoagulante citrato de sódio. Este lavado peritoneal foi mantido em caixa térmica com gelo e conduzido ao laboratório de farmacologia da Universidade Paranaense. No laboratório foi submetido à centrifugação a 1000rpm durante cinco minutos para isolamento dos neutrófilos, os quais foram mantidos em solução salina de Hanks. A viabilidade dos neutrófilos foi feita corando-os com azul de Tripano e contando-os em hemocitômetro de Neubauer, considerando-se a viabilidade adequada para este estudo maior que $97 \%$.

\section{Obtenção do Polímero}

O amido foi doado pela empresa AVEBE (Avebe Guaíra Amidos Ltda. de Guaíra-Paraná). O polímero foi obtido pesando-se 1,2g de amido de mandioca. Posteriormente adicionou-se $30 \mathrm{ml}$ de água destilada e aqueceu-se por duas horas em uma temperatura de aproximadamente $100^{\circ} \mathrm{C}$ sob agitação. Este procedimento foi utilizado com a finalidade de romper os grânulos de amido. Após o rompimento dos grânulos, a dispersão (amido+água+glutaraldeído) foi resfriada a temperatura ambiente $\left(25^{\circ} \mathrm{C}\right)$ e adicionou-se quantidades que variaram de $10-50 \%$ em massa de uma 
solução a 25\% de glutaraldeído. Após, acondicionouse a solução em placa de teflon e evaporou-se o solvente em uma estufa a $50^{\circ} \mathrm{C}$ por 48 horas. $\mathrm{O}$ filme obtido foi caracterizado através de medidas de grau de inchamento, DSC (Calorimetria Diferencial de Varredura), TGA(Análise Termogravimétrica), RaiosX, MEV (Microscopia de Varredura) e infravermelho.

Análise da Porcentagem de Degranulação dos Neutrófilos

Foram colocados em tubos de ensaio $200 \mu \mathrm{l}$

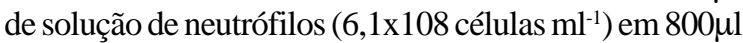
de solução de PBS (Phosphato Buffer Saline), e mantidos em banho-maria durante 10 minutos a $37^{\circ} \mathrm{C}$. As análises foram realizadas em duplicata e, após esta etapa, os tubos foram deixados em banho-maria durante 30 minutos a $37^{\circ} \mathrm{C}$ e a cada cinco minutos foram acrescentados inibidor, pré-estímulo e estímulo de acordo com o objetivo do estudo. Os tubos foram divididos em dois conjuntos com cinco grupos cada: grupo 1: controle negativo, grupo 2:fMLP+CB, grupo 3: amido $1(100 \%)$, grupo 4 : amido $1 / 2(50 \%)$, grupo 5 : amido $1 / 4(25 \%)$ e o segundo conjunto: grupo 1 :controle negativo, grupo 2: $\mathrm{fMLP}+\mathrm{CB}$, grupo 3: fMLP+CB+amido 1 , grupo 4: $\mathrm{fMLP}+\mathrm{CB}+$ amido $1 / 2 \mathrm{e}$ grupo 5: fMLP+CB+amido $1 / 4$.

Após esta etapa o material contido nos tubos dos dez grupos foi centrifugado e, a primeira parte (precipitada) permaneceu nos tubos e denominouse sobrenadante 1 , à qual foi acrescentado solução de PBS e solução de Triton, sendo novamente centrifugada. A segunda parte foi colocada em novos tubos de ensaio e denominou-se sobrenadante 2, sendo também acrescentado solução de PBS e solução de Triton. Incubou-se os tubos com os sobrenadantes $1 \mathrm{e}$ 2 por dez minutos a $37^{\circ} \mathrm{C}$ em banho-maria. Após esta etapa foi acrescentado solução de glicina e a quantidade de enzimas lisossomiais e EROs liberadas foi determinada após análise espectrofotométrica calibrada com comprimento de onda de 420 nanômetros, utilizando um aparelho da marca FANEM, São José do Rio Preto, e calculando a porcentagem pela fórmula*:

Porcentagem de enzima liberada = sobrenadante 1

Sobrenadante $1+$ Sobrenadante 2

*Conforme protocolo da Gifu University School of Medicine Japan

\section{Análise Estatística}

Os resultados foram avaliados pelo Teste de Análise de Variância (ANOVA) e foi considerado nível de significância para um valor de $\alpha=0,05$.

\section{RESULTADOS}

Observa-se que na tabela 1 os grupos amido 1(maior concentração de amido) e amido $1 / 2$ apresentaram porcentagem de degranulação semelhante ao grupo controle e, embora o grupo amido $1 / 4$ tenha sido o que apresentou menor porcentagem de degranulação, esta diferença não foi significativa estatisticamente $(\mathrm{P}<0,05)$ quando comparada aos outros grupos.

Já o grupo fMLP+CB foi o que apresentou maior porcentagem de degranulação com significância estatística $(\mathrm{P}<0,05)$, confirmando o já conhecido efeito degranulador de neutrófilos destes produtos, podendose assim inferir que o polímero de amido de mandioca teve um comportamento bioinerte.

Na tabela 2 mostrada a seguir nota-se que o grupo controle foi o que apresentou menor porcentagem de degranulação, resultado este com significado estatístico, porém quando comparados os grupos $\mathrm{fMLP}+\mathrm{CB}, \quad \mathrm{AMLP}+\mathrm{CB}+$ amido 1 , fMLP+CB+amido $1 / 2$ e fMLP+CB+amido $1 / 4$, observase que os grupos fMLP+CB+amido 1 e $\mathrm{fMLP}+\mathrm{CB}+$ amido $1 / 2$ foram os que tiveram menor porcentagem de degranulação com porcentagens muito próximas e, os grupos fMLP+CB e fMLP+CB+amido $1 / 4$ foram os grupos que tiveram maior porcentagem de degranulação, porém sem significância estatística entre os quatro grupos. Notou-se que quanto maior a concentração da solução do polímero menor a porcentagem de degranulação, mostrando que este amido tem perspectivas promissoras para novos estudos.

Tabela 1 - Média \pm desvio-padrão da porcentagem da degranulação de neutrófilos de coelhos submetidos ao estímulo padrão (fMLP+CB) ou polímero de amido de mandioca em diferentes concentrações. Umuarama, 2008.

\begin{tabular}{lc}
\hline & \% degranulação de neutrófilos \\
\hline Controle negativo & Média \pm Desvio-padrão \\
FMLP+CB & $27,45^{\mathrm{a}} \pm 14,37$ \\
Amido 1 & $53,50^{\mathrm{b}} \pm 12,92$ \\
Amido $1 / 2$ & $26,76^{\mathrm{a}} \pm 14,89$ \\
Amido $1 / 4$ & $26,04^{\mathrm{a}} \pm 14,96$ \\
\hline
\end{tabular}

Estatística: valores de média seguidos de letras diferentes indicam diferenças significativas entre os grupos pela Análise de Variância para um nível de significância $\alpha=0.05$. 
Tabela 2 - Média \pm desvio-padrão da porcentagem da degranulação de neutrófilos de coelhos submetidos ao estímulo padrão (fMLP+CB) associado a polímero de amido de mandioca em diferentes concentrações. Umuarama, 2008.

\begin{tabular}{lc}
\hline & \% degranulação de neutrófilos \\
\hline Controle negativo & Média \pm Desvio-padrão \\
FMLP+CB & $27,45^{\mathrm{a}} \pm 14,37$ \\
FMLP+CB + Amido 1 & $53,50^{\mathrm{b}} \pm 12,92$ \\
FMLP+CB + Amido $1 / 2$ & $49,68^{\mathrm{b}} \pm 16,89$ \\
FMLP+CB + Amido $1 / 4$ & $50,15^{\mathrm{b}} \pm 14,41$ \\
\hline
\end{tabular}

Estatística: Valores de média seguidos de letras diferentes indicam diferenças significativas entre os grupos pela Análise de Variância para um nível de significância $\alpha=0.05$.

\section{DISCUSSÃO}

Os neutrófilos constituem a primeira linha de resposta imune inata do hospedeiro e são ativados por vários fatores. A geração de EROs e consequente degranulação dos neutrófilos é mediada pelo complexo protéico-enzimático multicomponente da membrana conhecido por NADPHoxidase. Este complexo enzimático está inativo em neutrófilos em repouso. $\mathrm{O}$ ânion superóxido produzido pela ativação da NADPHoxidase serve de substrato para a geração de várias EROs que participam da atividade bactericida dos polimorfonucleares (FARINACCI et al., 2008). No presente estudo optou-se por testar ex vivo a influência do polímero de amido de mandioca em neutrófilos por existirem parâmetros relatados referentes a sua reação frente a agentes citotóxicos, através da degranulação e da produção de superóxido, além da sua facilidade de obtenção.

Outro motivo que levou ao estudo do amido de mandioca é que a região Noroeste do Paraná, da qual faz farte a cidade de Umuarama e sede da UNIPAR, apresenta várias fecularias que produzem o amido de mandioca. Foi investigada a possibilidade do polímero de amido de mandioca provocar a degranulação de neutrófilos. No primeiro ensaio (Tabela 1) notou-se que o grupo solução de neutrófilos+fMLP+CB foi o que apresentou porcentagem de degranulação estatisticamente significativa. Já são bem conhecidos na literatura (BRÉCHARD \& TSCHIRHART, 2008) os efeitos da CB e do fMLP sobre a degranulação do neutrófilos por ativação da enzima NADPHoxidase. Analisando os outros grupos pode-se inferir que o polímero de amido de mandioca teve um comportamento bioinerte. As enzimas da explosão respiratória na membrana plasmática de neutrófilos catalisam a oxidação da NADPHoxidase, que leva a produção de ânion superóxido. As EROs são responsáveis por matar microrganismos fagocitados (BRÉCHARD et al., 2008). Notou-se nesse estudo (Tabela 2) que o grupo controle negativo foi o que apresentou menor porcentagem de degranulação, resultado este com significado estatístico e que, quanto maior a concentração da solução do polímero, menor a porcentagem de degranulação, mostrando que este amido tem perspectivas promissoras para novos estudos, não só por sua não ativação neutrofílica mas também por sua ação inibidora da degranulação.

Os controles negativo e positivo são utilizados para verificar a eficácia do ensaio da degranulação. O controle negativo deve ser um material que não cause dano celular, ou seja, atóxico, neste trabalho continha apenas neutrófilos em solução de PBS associado ao polímero de amido mandioca, já os controles positivos devem ser de material tóxico que cause dano celular, ou seja, citotóxico, no caso o polímero, o qual se mostrou bioinerte, evidenciando resultados promissores, pois nas concentrações maiores de amido apresentou comportamento semelhante ao grupo controle, ou seja, não apresentou toxicidade nas diferentes concentrações. Desta forma, é possível sugerir que o polímero estudado não foi o responsável pela degranulação dos neutrófilos, sendo, portanto caracterizado como não-citotóxico (DAGUANO et al., 2007).

A estrutura química do amido pode ser alterada por métodos químicos, físicos, enzimáticos ou pela combinação de todos, com a formação de produtos com propriedades diferentes do amido nativo. Dependendo da intensidade destes métodos vários produtos podem ser obtidos, constituindo um vasto campo de desenvolvimento de pesquisa e de aplicação de conhecimento tecnológico (HENRIQUE et al., 2008).

É de se destacar também que os resultados ex vivo são diferentes do implante in vivo, assim, o próximo passo será fazer um implante in vivo de fragmentos do referido polímero para analisar a aceitação pelo organismo deste corpo estranho, permitindo entender melhor o mecanismo de degradação dele e a resposta inflamatória local e sistêmica resultante deste implante. Os testes in vitro podem não representar a situação real de um implante, contudo, eles podem promover alguns resultados preliminares relacionados à interação entre o material e 
o corpo biológico, de forma rápida e eficiente, minimizando a necessidade de testes em animais (DAGUANO et al., 2007). Em estudos in vivo a biodegradação e biorreabsorção é um mecanismo complexo de reações celulares e bioquímicas. Com o implante do material sintético o organismo promove uma reação inflamatória ao corpo estranho. A influência na degradação pela presença de peróxidos e células fagocitárias como neutrófilos, representa ainda hoje importante enfoque em pesquisas com polímeros (BARBANTI et al., 2005).

Embora vários dispositivos médicos que salvam vidas e melhoram a qualidade de vida sejam implantados anualmente, existe muito a ser aprimorado. Em geral, os atuais biomateriais não controlam a resposta biológica induzida por eles, já que esta não é planejada. Pesquisas com polímeros de amido se intensificaram nos últimos anos, pois o amido possui baixo custo, abundância, alta aplicabilidade, são fáceis de produzir e manusear e apresentam características semelhantes aos materiais biológicos. Além destas vantagens dos materiais sintéticos sobre os biológicos, apresentam maior segurança de assepsia, há possibilidade de produção personalizada do implante e rapidez de fabricação, porém quando comparado ao material biológico, este tem menor possibilidade de rejeição e custos de produção mais baixos (FRANÇA et al., 2005). A fécula de mandioca tem sido empregada na elaboração e obtenção de biofilmes, mas pouco se sabe das propriedades físicas destes e sobre seu uso em medicina (VILPOUX et al., 2008; SILVA et al., 2007).

\section{CONCLUSÃO}

Os polímeros biodegradáveis já apresentam uso em grande escala na medicina veterinária, seja em sistemas de liberação de medicamentos, seja no preenchimento de tecidos ou fabricação de próteses. Os mecanismos de degradação e a possível reação inflamatória resultantes do implante do polímero de amido de mandioca ainda não foram totalmente estudados e demanda investigações futura. Os testes de degranulação apresentaram bons resultados, mostrando que o polímero de amido de mandioca estudado apresenta grande tendência a ser material biocompatível, pois não estimulou a degranulação de neutrófilos e não apresentou toxicidade em nenhuma das diferentes concentrações, portanto caracterizandose como não-citotóxico.
Desenvolver novas técnicas e aprimorar as já desenvolvidas, continua sendo importante enfoque na utilização de polímeros biorreabsorvíveis.

\section{AGRADECIMENTO}

Ao Prof. Dr. Aristeu Vieira da Silva pela análise estatística e à Diretoria Executiva de Pesquisa e Pós-graduação (DEPPG) da Universidade Paranaense (UNIPAR), pelo financimaneto do projeto.

\section{COMITÊ DE ÉTICA E BIOSSEGURANÇA}

Este trabalho teve aprovação do Comitê de Ética em Pesquisa Envolvendo Experimentação Animal (CEPEEA) da Universidade Paranaense (UNIPAR) em 25/10/2007 sob o protocolo no $13583 / 2008$.

\section{REFERÊNCIAS}

BABIOR, B.M. Oxygen-dependent microbial killing by phagocytes. New England Journal of Medicine, v.298, p.721-725, 1978.

BARBANTI, S.H. et al. Polímeros biorreabsorvíveis na engenharia de tecidos. Polímeros, v.15, n.1, p.1-17, 2005. Disponível em: $<$ http://www.scielo.br/scielo.php?script=sci_arttext\&pid=S0104 $+14282005000100006 \&$ Ing $=p t \& n r m=i s o>$. Acesso em: 04 dez.2008. doi: 10.1590/S014-1428200500010000.

BRÉCHARD, S.; TSCHIRHART, E.J. Regulation of superoxide production in neutrophils: role of calcium influx. Journal of Leukocyte Biology, v.84, p.1-15, 2008. Disponível em <http://www.jleukbio.org/>. Acesso em: 10 jan. 2009.

DAGUANO, J.K.M.F. et al. Avaliação da citotoxicidade de biocerâmicas desenvolvidas para uso em sistemas de implantes. Revista Matéria, v.12, n.1, p.134-139, 2007. Disponível em: $<$ http://www.scielo.br/scielo.php?script=sci_arttex\&pid=S1517 $+70762007000100017 \&$ Ing=pt\&nrm=iso $>$. Acesso em: 10 nov. 2008. doi: 10.1590/S1517-70762007000100017.

EL-BENNA, J. et al. Phagocyte NADPH oxidase: a multicomponent enzyme essential for host defenses. Archives Immunologie Therapy Experimental, v.53, p.199-206, 2005.

FARINACCI, M. et al. Immunomodulatory activity of plant residues on ovine neutrophils. Veterinary Immunology and Immunopathology, v.126, p.54-63, 2008. Disponível em: <www.sciencedirect.com>. Acesso em: 14 jan. 2009.

FRANÇA, V.P. et al. Estudo comparativo experimental de compósito bioativo de matriz polimérica para aplicação em cirurgia plástica ocular na substituição tecidual. Arquivos Brasileiros de Oftalmologia, v.68, n.4, p. 425-431, 2005. Disponível em $<$ http://scielo.br/scielo.php?script=sci_arttex \&pid= $2000427492005000400003 \&$ Ing $=p t \& n r m=i s o>$. Acesso em: 20 set. 2008. doi: 10.1590/S0004-27492005000400003. 
HENRIQUE, C.M. et al. Características físicas de filmes biodegradáveis produzidos a partir de amidos modificados de mandioca. Ciência e Tecnologia de Alimentos, v.28, n.1, p. 231-240, 2008. Disponível em: <http://scielo.br/ s c i e lo.ph p ? s c ri p t = s c i_a r t t e x \& p i d = S 010 $1+20612008000100033 \&$ Ing $=$ en $\&$ nrm=iso $>$. Acesso em: 06 out. 2008. doi: 10.1590/S0101-20612008000100033.

SILVA, W.A. et al. Determinação da cor, imagem superficial topográfica e ângulo de contato de biofilmes de diferentes fontes de amido. Ciências Agrotécnicas, v.31, n.1, p.154-163, 2007. Disponível em: <http://scielo.br/scielo.php?script=sci_arttex\&pid=S141370542007000100023\&Ing=en\&nrm=iso>. Acesso em: 10 jan. 2008. doi: 10.1590/S1413-70542007000100023.

TAKEMURA, O.S. et al. Inhibition of N-FormylmethionylLeucyl-Phenylalanine-Stimulated tyrosine phosphorylation and phospholipase D activation by quercetin in rabbit neutrophil. biochemical Pharmacology, v.53, p.1503-1510, 1997. Disponível em: <www.sciencedirect.com.>. Acesso em: $10 \mathrm{dez}$. 2008

VILPOUX, O.; AVEROUS, L. Plásticos a base de amido. In: Cereda, M.P. Tecnologia, usos e potencialidades de tuberosas amiláceas Latino Americanas. Fundação Cargill, 2003. Cap.18, p.499-529.

WINZENBURG, C. et al. Biodegradable polymers and their potential use in parenteral veterinary drug delivery systems. Advanced Drug Delivery Reviews, v.56, p.1453-1466, 2004. Disponível em: <www.sciencedirect.com>. Acesso em: 15 dez. 2008

WOO, R.K. et al. Biomaterials: historical overview and current direction. In: GRECO,R.S et al. (Eds). Nanoscale technology in biological system. Boca Raton: CRC, 2005. p.1-24, 2005. 